\title{
The Relationship Between Fasting Blood Glucose Levels and First Ischemic Stroke in Elderly Hypertensive Patients
}

This article was published in the following Dove Press journal: Risk Management and Healthcare Policy

\author{
Yu-qing Huang ${ }^{1, *}$ \\ Kenneth Lo iD ${ }^{1, *}$ \\ Xiao-cong Liu (iD) \\ Song-tao Tang $^{2}$ \\ Cheng Huang' \\ Ying-qing Feng (iD) \\ 'Department of Cardiology, Guangdong \\ Cardiovascular Center, Guangdong \\ Cardiovascular Institute, Guangdong \\ Provincial People's Hospital, Guangdong \\ Academy of Medical Sciences, School of \\ Medicine, South China University of \\ Technology, Guangzhou, People's Republic \\ of China; ${ }^{2}$ Department of Internal \\ Medicine, Community Health Center of \\ Liaobu County, Dongguan, People's \\ Republic of China \\ *These authors contributed equally to this \\ work
}

\begin{abstract}
Objective: The relationship between fasting blood glucose and first ischemic stroke in older adults was unclear, so we explored this association among older patients with hypertension in China.

Methods: We recruited hypertensive participants with 60 or more of age. Fasting blood glucose concentrations were categorized into quartiles. Hazard ratio (HR) and $95 \%$ confidence interval (CI) for ischemic stroke were estimated using multivariate Cox regression analysis and subgroup analysis.
\end{abstract}

Results: A total of 3310 (1474 (44.53\%) male) patients with mean age of $71.41 \pm 7.20$ years were included. During the mean follow-up period of 5.5 years, 206 cases of ischemic stroke occurred. After adjusting for potential confounding variables, multivariate adjusted HRs for each standard deviation increment of fasting blood glucose, the risk of ischemic stroke increased by $11 \%(95 \% \mathrm{CI}: 1.03,1.21 ; \mathrm{P}=0.008)$. In addition, when using the lowest group (Q1) as reference, the multivariate adjusted HRs for first ischemic stroke were 1.76 (95\% CI: 1.08, 2.86; $\mathrm{P}=0.023), 1.73$ (95\% CI: 1.06, 2.81; $\mathrm{P}=0.027)$ and 2.42 (95\% CI: 1.49 , 3.93 ; $\mathrm{P}<0.001$ ) ( $\mathrm{P}$ for trend $<0.001$ ). Subgroup analysis revealed that the association between fasting blood glucose and the risk of ischemic stroke was higher in male (HR: 1.22 vs 1.10), those with uncontrolled hypertension (HR: 1.22 vs 1.10), subjects with diabetes (HR: 1.19 vs 1.10), overweight (HR: 1.19 vs 1.09), smoking habits (HR: 1.33 vs 1.13 ) and those whose eGFR< 90 (HR: 1.16 vs 1.09).

Conclusion: Fasting blood glucose was an independent risk factor for the first ischemic stroke among older adults with hypertension. Managing fasting blood glucose may be beneficial for participants with diabetes, poorly controlled blood pressure, had smoking habits, being overweight, and with reduced renal function.

Keywords: fasting blood glucose, ischemic stroke, elderly, hypertension, community

\section{Introduction}

Stroke is the main cause of death in China, ${ }^{1}$ with ischemic stroke to be the most common subtype. ${ }^{2}$ Ischemic stroke is a type of arteriosclerotic disease and a heterogeneous disease. ${ }^{3}$ Studies have shown that elevated blood pressure, age, obesity, smoking, hyperlipidemia, impaired fasting glucose, elevated fasting blood glucose (FBG), diabetes and hyperglycemia were independent risk factors for ischemic stroke. ${ }^{3}$ Although previous studies have reported significant associations between FBG and arteriosclerotic cardiovascular disease, ${ }^{4-7}$ the relationship between FBG and ischemic stroke was still controversial. Some studies reported that the relationship between

\footnotetext{
Correspondence: Ying-qing Feng; Cheng

Department of Cardiology, Guangdong

Cardiovascular Center, Guangdong

Cardiovascular Institute, Guangdong

Provincial People's Hospital, Guangdong

Academy of Medical Sciences, School of

Medicine, South China University of

Technology, Guangzhou 510080, People's

Republic of China

$\mathrm{Tel} / \mathrm{Fax}+86-20-83827812$

Email651792209@qq.com;

linfeng7822@sina.com
} 
stroke and FBG was linear, U-shaped or J-shaped among general population, ${ }^{8}$ asymptomatic adults, ${ }^{9}$ patients with preexisting atherothrombotic diseases, ${ }^{10}$ or non-diabetic population. ${ }^{6,11}$ In addition, there was a study demonstrated that FBG had no null association with the risk of cardiovascular diseases, such as coronary heart disease and ischemic stroke in hypertensive patients. ${ }^{12}$ Given the inconsistent relationship between fasting blood glucose and first ischemic stroke in older adults with hypertension, we explored the association among older hypertensive patients with hypertension in China.

\section{Materials and Methods}

\section{Study Subjects}

This retrospective cohort study enrolled 3500 older patients from January, 2010, to December, 2011, at Guangdong community in China. We recruited essential hypertensive patients who were at least 60 years of age. We excluded participants with missing data on blood pressure $(n=37)$, FBG $(n=5)$ or physical examination $(\mathrm{n}=16)$, and those who had a stroke history at baseline $(n=132)$. Eventually, 3310 participants were included for data analysis (Figure 1). Informed consent was obtained from all included participants. This study was in compliance with the principles outlined in the Declaration of Helsinki and was approved by the institutional medical ethical committee the Guangdong Provincial People's Hospital, Guangzhou, China.

\section{Measurement of Indicators}

Demographic information was obtained from all patients through questionnaires, including age, sex, habits on smoking and drinking, a previous history of diseases (such as diabetes, coronary heart disease, and stroke), and combined medication history (such as antihypertensive drugs, hypoglycemic drugs, and lipid-lowering drugs). Parameters being measured in the physical examination and laboratory tests included height, weight, and blood pressure, urinalysis, FBG, blood lipid and creatinine after overnight fasting. Drinking status was defined as having consumed at least $50 \mathrm{~g}$ alcohol daily in the last 30 days and smoking was defined as using at least 100 cigarettes during their lifetime in the last 30 days before the survey of the present study. ${ }^{13}$ Hypertension was defined as systolic blood pressure (SBP) $\geq 140 \mathrm{mmHg}$ or/and diastolic blood pressure (DBP) $\geq$ $90 \mathrm{mmHg}$, or currently taking antihypertensive medication or self-reported. ${ }^{14}$ Diabetes was defined as FBG $\geq 11.1 \mathrm{mmol} /$ L, or currently taking hypoglycemic agents or self-reported.-

15 Body mass index (BMI) was calculated as the weight in kilograms divided by the height in meters squared. Estimate glomerular filtration rate (eGFR) was calculated by using the simplified equation on the modification of diet.

All stroke cases were ascertained from the local medical insurance system of the medical insurance bureau, and patients without medical records were followed up by telephone or by face- to- face in the community until 31 December 2016. Hospitalization with a diagnosis of ischemic stroke was confirmed by computed tomography or magnetic resonance image and checked by discharge data.

\section{Statistical Analysis}

All the continuous variables were presented as mean \pm standard deviation, and categorical variables were presented in

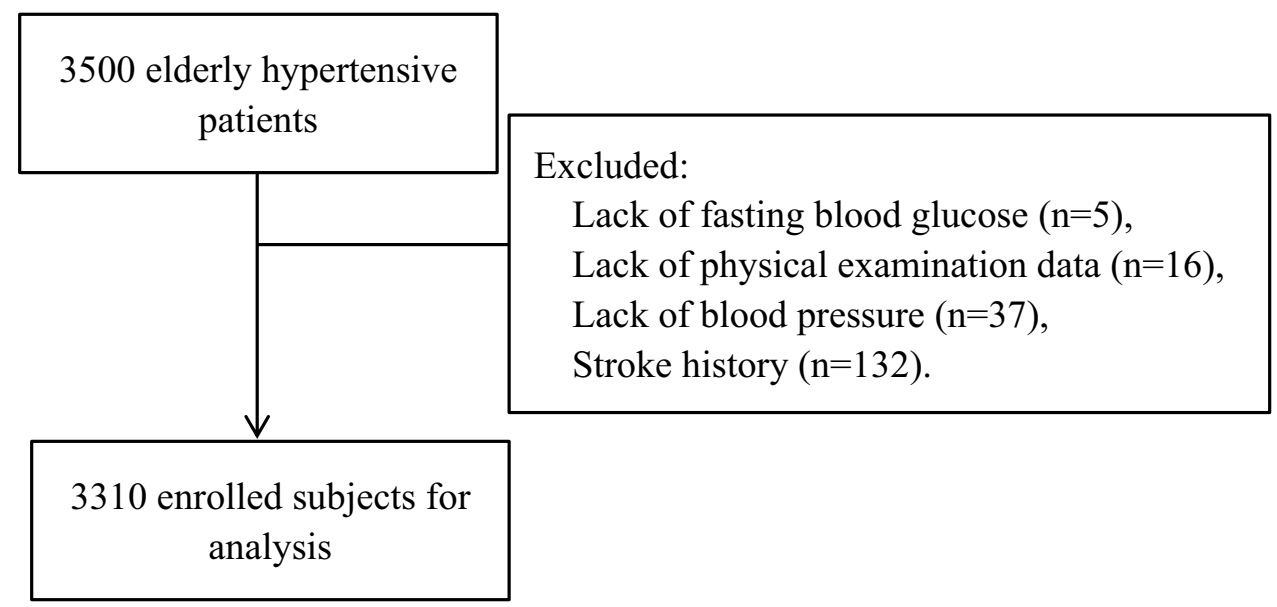

Figure I Research flow chart. 
frequency or as a percentage according to baseline FBG categories. FBG concentrations were grouped by quartiles (Q1: < 4.39mmol/l, Q2: 4.40-5.79 mmol/l, Q3: 5.80 $6.36 \mathrm{mmol} / \mathrm{l}$, and Q4: $\geq 6.37 \mathrm{mmol} / \mathrm{l})$. Subgroup differences by FBG quartiles were identified by the One-Way ANOVA, Kruskal-Wallis $H$-test and chi-square tests. Hazard ratios (HRs) and 95\% confidence intervals (CIs) for ischemic stroke were estimated using multivariate Cox regression analysis. The Model I only included FBG. The model II was adjusted for age, sex and BMI. The model III was adjusted for sex, BMI, age, diabetes history, coronary heart disease history, antihypertensive drugs, statins, SBP, DBP, triglyceride (TG), high-density lipoprotein cholesterol (HDL-C), total cholesterol (TC), low-density lipoprotein cholesterol (LDL-C), smoking, drinking and eGFR. Subgroup analysis was conducted according to sex (male or female), age $(<70,70-80$ or $\geq 80$ years), SBP $(<140$ or $\geq 140 \mathrm{~mm} \mathrm{Hg}$ ), eGFR ( $<90$ or $\left.\geq 90 \mathrm{~mL} / \mathrm{min} / 1.73 \mathrm{~m}^{2}\right)$, BMI $\left(<25\right.$ or $\geq 25 \mathrm{~kg} / \mathrm{m}^{2}$ ), the history of diabetes (yes or no), drinking status (yes or no), smoking status (yes or no), using statins (yes or no) and taking antihypertensive drug (yes or no), and the interactions between FBG and subgroups on the association with stroke were tested. A 2-sided $\mathrm{P}<0.05$ was considered statistically significant. All statistical analyses were performed using $\mathrm{R}$ version 3.3.2 (R Foundation for Statistical Computing, Vienna, Austria).

\section{Results}

\section{Characteristics of the Participants}

After applying the inclusion and exclusion criteria, 3310 older hypertensive patients were included, 1474 (44.53\%) were males. The mean age was $71.41 \pm 7.20$ years old. Baseline characteristics of the participants are presented in Table 1. There were significant differences in age, BMI, SBP, DBP, triglyceride, LDL-C, HDL-C, sex, smoking status, diabetes history and taking antihypertensive drugs and statins across the quartile groups.

\section{The Relationship Between Fasting Blood Glucose Levels and Ischemic Stroke}

As showed in Table 2, during an average follow-up of 5.5 years, 206 cases of ischemic strokes occurred. When FBG was treated as continuous variable, FBG was significantly associated with ischemic stroke in model I ( $\mathrm{HR}=1.15,95 \%$ CI: $1.08,1.23 ; \mathrm{P}<0.001)$. In model II, FBG was still an independent risk factor for ischemic stroke $(\mathrm{HR}=1.14$, $95 \%$ CI: $1.07,1.23 ; \mathrm{P}<0.001)$, as well as the fully adjusted model (model III), where FBG (HR=1.11, 95\% CI: 1.03 , $1.21 ; \mathrm{P}=0.008$ ) was positively associated with the first occurrence of ischemic stroke (Table 2). When using the lowest quartile of FBG as reference, the HRs for ischemic stroke from Q2 to Q4 were 1.77 (95\% CI: 1.10, 2.87, 1.90 (95\% CI: 1.18, 3.07) and 3.08 (95\% CI: 1.97, 4.83) (P for trend $<0.001)$ in model I. In model III, the HRs for the first occurrence of ischemic stroke increased in parallel with the quartiles of FBG (HRs were 1.76 (95\% CI: 1.08, 2.86), 1.73 (95\% CI: 1.06, 2.81), and 2.42 (95\% CI: 1.49, 3.93) from the second to the fourth quartiles, respectively, $\mathrm{P}$ for trend $<0.001$ ) (Table 2). Multivariate adjusted smoothing spline plots suggested that FBG levels have a nonlinear relationship with the first occurrence of ischemic stroke (Figure 2).

\section{The Results of Subgroup Analyses}

As shown in Table 3, subgroup analysis revealed that the association between FBG and risk of ischemic stroke was appear to be stronger in male (HR: 1.22 vs 1.10 ), those with uncontrolled hypertension (HR: 1.22 vs 1.10), subjects with diabetes (HR: 1.19 vs 1.10 ), overweight (HR: 1.19 vs 1.09 ), smoking habits (HR: 1.33 vs 1.13), drinking habits (HR: 1.17 vs 1.05 ), without using statins (HR: 1.19 vs 1.09 ), without taking antihypertensive drugs (HR: 1.16 vs 1.10 ) and those with eGFR< 90 (HR: 1.16 vs 1.09 ).

\section{Discussion}

In the present study, elevated FBG levels were significantly associated with increased risk for the first incident of ischemic stroke and this relationship appeared as a gradually increasing nonlinear relationship. The risk might further elevate for subjects combined with diabetes, poorly controlled blood pressure, smoking, being overweight, and with reduced renal function.

We found that the risk for first ischemic stroke gradually increased with FBG concentration. The result of the present study agreed with previous cohort analyses among adults with hypertension. ${ }^{12,16}$ Our study did not find a clear threshold for the relationship between FBG and ischemic stroke among older adults with hypertension. Our results might suggest a J-curve nor a U-curve relationship, which was also suggested in some other studies. ${ }^{4,8,10,17,18}$ In addition, a meta-analysis of 102 prospective studies demonstrated that among people without diabetes, FBG concentration had modest and non-linear relation with stroke risk. ${ }^{19}$ The reason why our research results differ from previous may be 
Table I Baseline Characteristics of Participant Patients by Quartiles of Fasting Blood Glucose

\begin{tabular}{|c|c|c|c|c|c|c|}
\hline & All & QI & Q2 & Q3 & Q4 & P-value \\
\hline Number & 3310 & $810(<4.39 \mathrm{mmol} / \mathrm{l})$ & $836(4.40-5.79 \mathrm{mmol} / \mathrm{l})$ & $829(5.80-6.36 \mathrm{mmol} / \mathrm{l})$ & $835(\geq 6.37 \mathrm{mmol} / \mathrm{l})$ & \\
\hline Age(years) & $71.41 \pm 7.20$ & $72.25 \pm 7.06$ & $71.61 \pm 7.01$ & $71.40 \pm 7.09$ & $70.39 \pm 7.50$ & $<0.001$ \\
\hline $\operatorname{BMl}\left(\mathrm{kg} / \mathrm{m}^{2}\right)$ & $23.91 \pm 3.80$ & $23.30 \pm 3.72$ & $23.36 \pm 3.44$ & $23.94 \pm 3.63$ & $24.03 \pm 4.14$ & $<0.001$ \\
\hline $\mathrm{SBP}(\mathrm{mmHg})$ & $131.08 \pm 17.23$ & $128.47 \pm 15.76$ & $129.94 \pm 16.99$ & $132.02 \pm 17.36$ & $133.83 \pm 18.23$ & $<0.001$ \\
\hline $\mathrm{DBP}(\mathrm{mmHg})$ & $78.33 \pm 9.55$ & $77.47 \pm 9.19$ & $78.05 \pm 9.53$ & $78.58 \pm 9.54$ & $79.21 \pm 9.85$ & 0.002 \\
\hline $\mathrm{TC}(\mathrm{mg} / \mathrm{dl})$ & $203.07 \pm 45.66$ & $203.28 \pm 47.84$ & $204.31 \pm 42.27$ & $202.19 \pm 43.43$ & $202.50 \pm 48.88$ & 0.791 \\
\hline Triglyceride (mg/dl) & $150.11 \pm 116.12$ & $136.15 \pm 114.06$ & $136.80 \pm 95.11$ & $147.48 \pm 107.17$ & $180.39 \pm 138.77$ & $<0.001$ \\
\hline LDL-C(mg/dl) & $103.63 \pm 29.43$ & $102.52 \pm 27.95$ & $105.04 \pm 29.19$ & $105.09 \pm 29.89$ & $101.85 \pm 30.55$ & 0.047 \\
\hline $\mathrm{HDL}-\mathrm{C}(\mathrm{mg} / \mathrm{dl})$ & $50.76 \pm 14.03$ & $51.31 \pm 16.71$ & $51.51 \pm 12.78$ & $50.83 \pm 13.03$ & $49.38 \pm 13.15$ & 0.010 \\
\hline $\mathrm{eGFR}\left(\mathrm{mL} / \mathrm{min} / 1.73 \mathrm{~m}^{2}\right)$ & $90.42 \pm 34.21$ & $91.95 \pm 39.49$ & $88.29 \pm 36.65$ & $86.60 \pm 30.70$ & $94.82 \pm 37.49$ & 0.426 \\
\hline $\operatorname{Sex}(n, \%)$ & & & & & & 0.002 \\
\hline Male & $1474(44.53 \%)$ & 388 (47.90\%) & $396(47.37 \%)$ & $360(43.43 \%)$ & $330(39.52 \%)$ & \\
\hline Female & $1836(55.47 \%)$ & $422(52.10 \%)$ & $440(52.63 \%)$ & $469(56.57 \%)$ & $505(60.48 \%)$ & \\
\hline Smoking(n, \%) & & & & & & 0.002 \\
\hline No & $2377(71.81 \%)$ & $552(68.15 \%)$ & $582(69.62 \%)$ & $610(73.58 \%)$ & $633(75.81 \%)$ & \\
\hline Yes & $933(28.19 \%)$ & $258(31.85 \%)$ & $254(30.38 \%)$ & $219(26.42 \%)$ & $202(24.19 \%)$ & \\
\hline Drinking(n, \%) & & & & & & 0.719 \\
\hline No & $2972(89.79 \%)$ & $730(90.12 \%)$ & $742(88.76 \%)$ & 746 (89.99\%) & 754 (90.30\%) & \\
\hline Yes & $338(10.21 \%)$ & $80(9.88 \%)$ & $94(11.24 \%)$ & $83(10.01 \%)$ & 81 (9.70\%) & \\
\hline Diabetes(n, \%) & & & & & & $<0.001$ \\
\hline No & $2805(84.74 \%)$ & 771 (95.19\%) & 781 (93.42\%) & 747 (90.11\%) & $506(60.60 \%)$ & \\
\hline Yes & $505(15.26 \%)$ & $39(4.81 \%)$ & $55(6.58 \%)$ & $82(9.89 \%)$ & $329(39.40 \%)$ & \\
\hline $\operatorname{CAD}(\mathrm{n}, \%)$ & & & & & & 0.352 \\
\hline No & 3276 (98.97\%) & 804 (99.26\%) & $828(99.04 \%)$ & $822(99.16 \%)$ & $822(98.44 \%)$ & \\
\hline Yes & $34(1.03 \%)$ & $6(0.74 \%)$ & $8(0.96 \%)$ & $7(0.84 \%)$ & $13(1.56 \%)$ & \\
\hline Antihypertensive drugs(n, \%) & & & & & & $<0.001$ \\
\hline No & $2158(65.20 \%)$ & $584(72.10 \%)$ & $579(69.26 \%)$ & $531(64.05 \%)$ & $464(55.57 \%)$ & \\
\hline Yes & $1152(34.80 \%)$ & $226(27.90 \%)$ & $257(30.74 \%)$ & $298(35.95 \%)$ & $371(44.43 \%)$ & \\
\hline Beta-blocker(n, \%) & & & & & & $<0.001$ \\
\hline No & $3155(95.32 \%)$ & 778 (96.05\%) & $808(96.65 \%)$ & 797 (96.14\%) & $772(92.46 \%)$ & \\
\hline Yes & $155(4.68 \%)$ & $32(3.95 \%)$ & $28(3.35 \%)$ & $32(3.86 \%)$ & $63(7.54 \%)$ & \\
\hline $\mathrm{CCB}(\mathrm{n}, \%)$ & & & & & & $<0.001$ \\
\hline No & $2656(80.24 \%)$ & $693(85.56 \%)$ & $692(82.78 \%)$ & $654(78.89 \%)$ & $617(73.89 \%)$ & \\
\hline Yes & $654(19.76 \%)$ & $117(14.44 \%)$ & $144(17.22 \%)$ & $175(21.11 \%)$ & $218(26.11 \%)$ & \\
\hline $\operatorname{ACEI}(n, \%)$ & & & & & & 0.006 \\
\hline No & 3099 (93.63\%) & 775 (95.68\%) & 789 (94.38\%) & 769 (92.76\%) & 766 (91.74\%) & \\
\hline Yes & $211(6.37 \%)$ & 35 (4.32\%) & 47 (5.62\%) & $60(7.24 \%)$ & $69(8.26 \%)$ & \\
\hline $\operatorname{ARB}(n, \%)$ & & & & & & $<0.001$ \\
\hline No & 2667 (80.57\%) & $676(83.46 \%)$ & $699(83.61 \%)$ & 657 (79.25\%) & 635 (76.05\%) & \\
\hline Yes & $643(19.43 \%)$ & $134(16.54 \%)$ & $137(16.39 \%)$ & $172(20.75 \%)$ & $200(23.95 \%)$ & \\
\hline Statins(n, \%) & & & & & & $<0.001$ \\
\hline No & 3025 (91.39\%) & 752 (92.84\%) & 771 (92.22\%) & 771 (93.00\%) & 73 I (87.54\%) & \\
\hline Yes & $285(8.61 \%)$ & $58(7.16 \%)$ & $65(7.78 \%)$ & $58(7.00 \%)$ & $104(12.46 \%)$ & \\
\hline
\end{tabular}

Abbreviations: BMI, body mass index; SBP, systolic blood pressure; DBP, diastolic blood pressure; CAD, coronary heart disease; TC, total cholesterol; HDL-C, high-density lipoprotein cholesterol; LDL-C, low-density lipoprotein cholesterol; eGFR, estimated glomerular filtration rate; CCB, calcium channel blocker; ACEI, angiotensin-converting enzyme inhibitor; ARB, angiotensin receptor blocker. 
Table 2 Relationship Between Fasting Blood Glucose Levels and the First Occurrence of Ischemic Stroke in Different Models

\begin{tabular}{|c|c|c|c|c|}
\hline & & Model I & Model II & Model III \\
\hline & Case/Total & HR(95\% Cl) P-value & HR(95\% Cl) P-value & HR(95\% Cl) P-value \\
\hline FBG(per SD increased) & $206 / 3310$ & $1.15(1.08,1.23)<0.001$ & I.I $4(1.07,1.23)<0.00 \mathrm{I}$ & $1.11(1.03,1.21) 0.008$ \\
\hline \multicolumn{5}{|l|}{ FBG (quartile) } \\
\hline QI & $27 / 810$ & ref & ref & ref \\
\hline Q2 & $48 / 836$ & $1.77(1.10,2.87) 0.019$ & $1.79(1.10,2.90) 0.018$ & $1.76(1.08,2.86) 0.023$ \\
\hline Q3 & $51 / 829$ & $1.90(1.18,3.07) 0.008$ & $1.87(1.16,3.02) 0.010$ & $\mathrm{I} .73(\mathrm{I} .06,2.8 \mathrm{I}) 0.027$ \\
\hline Q4 & $80 / 835$ & $3.08(1.97,4.83)<0.001$ & $2.89(1.83,4.55)<0.001$ & $2.42(1.49,3.93)<0.001$ \\
\hline$P$ for trend & & $<0.001$ & $<0.001$ & $<0.001$ \\
\hline
\end{tabular}

Notes: Model I adjust for: none. Model II adjust for: sex, BMI, age. Model III adjust for: sex, BMI, age, diabetes history, coronary heart disease history, antihypertensive drugs, statins, SBP, DBP, TC, TG, LDL-C, HDL-C, smoking, drinking and eGFR.

Abbreviations: FBG, fasting blood glucose; Q, quartile; SD, standard deviation, $\mathrm{HR}$, hazard ratios; $\mathrm{Cl}$, confidence interval.

due to the selected population and ethnicities of these studies are different.

In our study, older hypertensive patients combined with diabetes, poorly controlled blood pressure, smoking, being overweight, with reduced renal function might have a higher risk for ischemic stroke. Smoking, elevated SBP, obesity and diabetes were established risk factors for ischemic stroke, ${ }^{3}$ which was likely the explanation for our findings. Our results were also consistent with previous studies ${ }^{20-23}$ and current international recommendations for stroke prevention and treatment. ${ }^{3,24}$ Individuals should stop smoking, limit or avoid alcohol, maintaining good control on weight, blood pressure, blood sugar and blood lipids for stroke prevention. ${ }^{25-28}$

However, some limitations should be taken into consideration in the present study. First, FBG was measured only once at baseline, so we were not able to examine the effects of FBG changes with stroke. Second, we did not adjust for several confounding factors were adjusted, such as the history of atrial fibrillation, the levels of uric acid

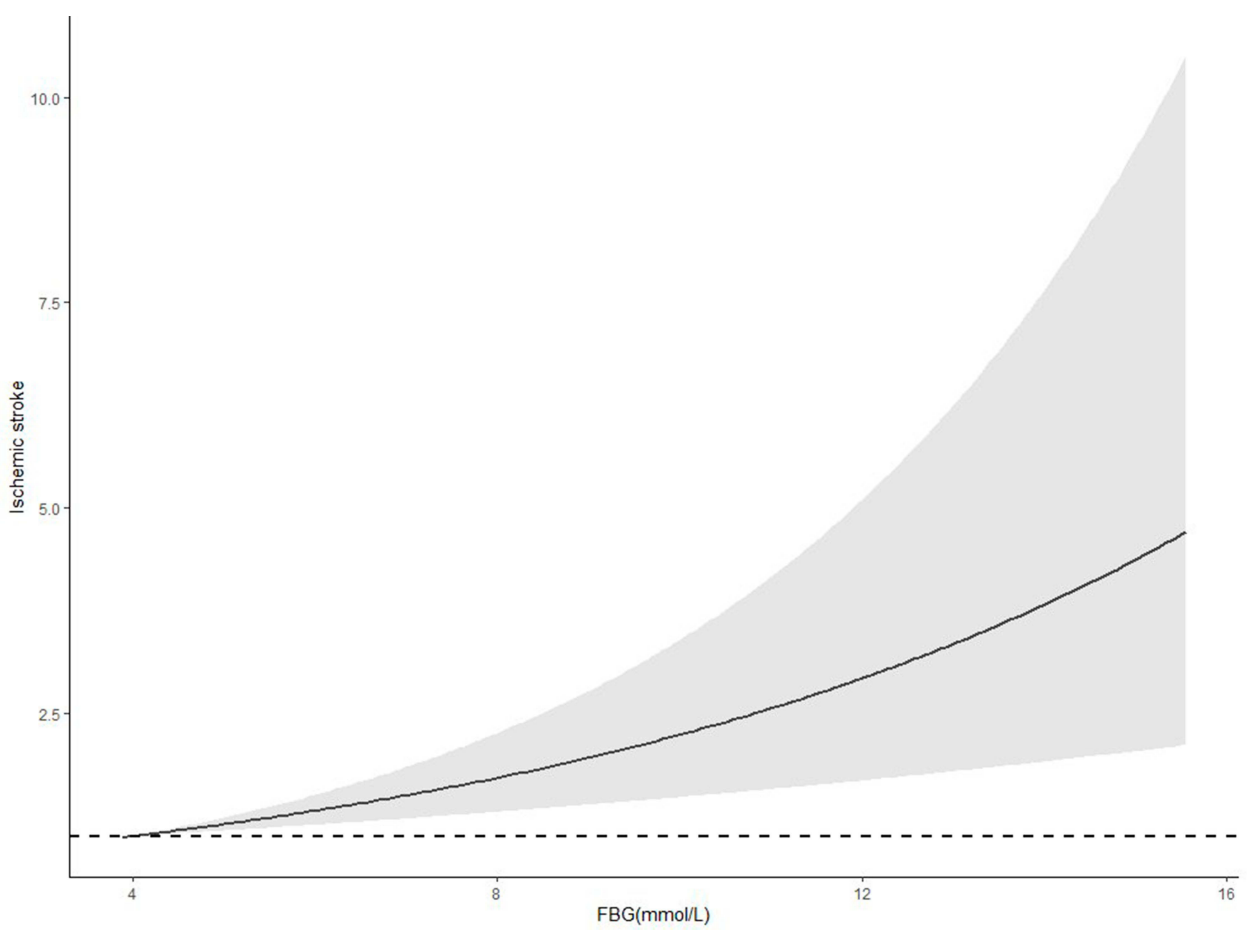

Figure 2 The relationship between fasting blood glucose levels and the first occurrence of ischemic stroke. Abbreviations: FBG, fasting blood glucose; HR, hazard ratios; $\mathrm{Cl}$, confidence interval. 
Table 3 Effect Size of Fasting Blood Glucose Levels on the First Occurrence of Ischemic Stroke in Subgroups

\begin{tabular}{|c|c|c|c|c|}
\hline & Number & $\operatorname{HR}(95 \% \mathrm{Cl})$ & P-value & P Interaction \\
\hline Sex & & & & 0.318 \\
\hline Male & 1474 & $1.22(1.09,1.36)$ & $<0.001$ & \\
\hline Female & 1836 & $1.10(1.04,1.23)$ & 0.003 & \\
\hline Age & & & & 0.298 \\
\hline$<70$ & 1640 & $1.23(1.09,1.38)$ & $<0.001$ & \\
\hline$\geq 70,<80$ & 1204 & $1.11(1.01,1.22)$ & 0.037 & \\
\hline$\geq 80$ & 466 & $1.07(1.05,1.46)$ & 0.043 & \\
\hline Diabetes & & & & 0.084 \\
\hline No & 2805 & $1.10(1.05,1.34)$ & 0.034 & \\
\hline Yes & 505 & $1.19(1.07,1.18)$ & 0.002 & \\
\hline Smoking & & & & 0.091 \\
\hline No & 2377 & $1.13(1.05,1.22)$ & 0.001 & \\
\hline Yes & 933 & $1.33(1.12,1.57)$ & $<0.001$ & \\
\hline Drinking & & & & 0.939 \\
\hline No & 2972 & $1.05(1.08,1.23)$ & 0.031 & \\
\hline Yes & 338 & $1.17(1.03,1.53)$ & 0.027 & \\
\hline Taking antihypertensive drugs & & & & 0.843 \\
\hline No & 2158 & $1.16(1.08,1.24)$ & $<0.001$ & \\
\hline Yes & 1152 & $1.10(1.04,1.50)$ & 0.033 & \\
\hline Statins & & & & 0.571 \\
\hline No & 3025 & $1.19(1.07,1.23)$ & 0.002 & \\
\hline Yes & 285 & $1.09(1.04,1.46)$ & 0.040 & \\
\hline SBP & & & & 0.458 \\
\hline$<140$ & 2356 & $1.10(1.04,1.35)$ & 0.003 & \\
\hline$\geq 140$ & 954 & $1.22(1.06,1.43)$ & $<0.001$ & \\
\hline BMI & & & & 0.300 \\
\hline$<25$ & 2122 & $1.09(1.02,1.21)$ & 0.005 & \\
\hline$\geq 25$ & 1188 & $1.19(1.08,1.32)$ & 0.031 & \\
\hline eGFR & & & & 0.927 \\
\hline$<90$ & 1518 & $1.16(1.04,1.34)$ & 0.008 & \\
\hline$\geq 90$ & 1792 & $1.09(1.03,1.27)$ & 0.016 & \\
\hline
\end{tabular}

Notes: When analysis a subgroup variable, sex, BMI, age, diabetes history, coronary heart disease history, antihypertensive drugs, statins, SBP, DBP, TC, TG, LDL-C, HDL-C, smoking, drinking and eGFR were all adjusted expect itself.

Abbreviations: BMI, body mass index; SBP, systolic blood pressure; eGFR, estimated glomerular filtration rate; $\mathrm{HR}$, hazard ratios; $\mathrm{Cl}$, confidence interval.

and homocysteine. Third, the history of diabetes in this study was mainly obtained from self-reported history and we did not have the data of glycated hemoglobin. Finally, the present study did not distinguish the relationship between FBG and different subtypes of stroke.

\section{Conclusion}

In conclusion, among elderly hypertensive patients, FBG was closely related to the first occurrence of ischemic stroke. The relationship was stronger for subjects combined with diabetes, poorly controlled blood pressure, smoking, being overweight, and with reduced renal function.

\section{Abbreviations}

BMI, body mass index; SBP, systolic blood pressure; DBP, diastolic blood pressure; TC, total cholesterol; HDL-C, highdensity lipoprotein cholesterol; LDL-C, low-density lipoprotein cholesterol; eGFR, estimated glomerular filtration rate; Q, quartile; HR, hazard ratios; CI, confidence interval. 


\section{Author Contributions}

All authors made substantial contributions to conception and design, acquisition of data, or analysis and interpretation of data; took part in drafting the article or revising it critically for important intellectual content; gave final approval of the version to be published; and agree to be accountable for all aspects of the work.

\section{Funding}

This work was supported by the Natural Science Foundation of Guangdong Province (No. 2020A1515010738), the National Nature Science Foundation of China (No. 81300230), the Science and Technology Program of Guangzhou (No.201803040012), and the National Key Research and Development Program of China (No.2017FYC1307603, No.2016YFC1301305), the Key Area R\&D Program of Guangdong Province (No.2019B020227005).

\section{Disclosure}

The authors declare that they have no conflict of interest.

\section{References}

1. Li Z, Jiang Y, Li H, Xian Y, Wang Y. China's response to the rising stroke burden. BMJ. 2019;364:1879. doi:10.1136/bmj.1879

2. Wang W, Jiang B, Sun H, et al. Prevalence, Incidence, and mortality of stroke in china: results from a nationwide population-based survey of 480687 adults. Circulation. 2017;135(8):759-771. doi:10.1161/ CIRCULATIONAHA.116.025250

3. Wein T, Lindsay MP, Cote R, et al. Canadian stroke best practice recommendations: secondary prevention of stroke, sixth edition practice guidelines, update 2017. Int J Stroke. 2018;13(4):420-443. doi: $10.1177 / 1747493017743062$

4. Park C, Guallar E, Linton JA, et al. Fasting glucose level and the risk of incident atherosclerotic cardiovascular diseases. Diabetes Care. 2013;36(7):1988-1993. doi:10.2337/dc12-1577

5. Baumert J, Heidemann C, Paprott R, Du Y, Scheidt-Nave C. Association between random glucose and all-cause mortality: findings from the mortality follow-up of the German National Health Interview and Examination Survey 1998. BMC Endocr Disord. 2018;18(1):95. doi:10.1186/s12902-018-0319-2

6. Lee G, Kim SM, Choi S, et al. The effect of change in fasting glucose on the risk of myocardial infarction, stroke, and all-cause mortality: a nationwide cohort study. Cardiovasc Diabetol. 2018;17(1):51. doi:10.1186/s12933-018-0694-z

7. Mongraw-Chaffin M, LaCroix AZ, Sears DD, et al. A prospective study of low fasting glucose with cardiovascular disease events and all-cause mortality: the Women's Health Initiative. Metabolism. 2017;70:116-124. doi:10.1016/j.metabol.2017.02.010

8. Sung J, Song YM, Ebrahim S, Lawlor DA. Fasting blood glucose and the risk of stroke and myocardial infarction. Circulation. 2009;119 (6):812-819. doi:10.1161/CIRCULATIONAHA.108.776989

9. Sui X, Lavie CJ, Hooker SP, et al. A prospective study of fasting plasma glucose and risk of stroke in asymptomatic men. Mayo Clin Proc. 2011;86(11):1042-1049. doi:10.4065/mcp.2011.0267
10. Tanne D, Koren-Morag N, Goldbourt U. Fasting plasma glucose and risk of incident ischemic stroke or transient ischemic attacks: a prospective cohort study. Stroke. 2004;35(10):2351-2355. doi:10.1161/01.STR.0000140738.94047.55

11. Shaye K, Amir T, Shlomo S, Yechezkel S. Fasting glucose levels within the high normal range predict cardiovascular outcome. Am Heart J. 2012;164(1):111-116. doi:10.1016/j.ahj.2012.03.023

12. Tziomalos K, Spanou M, Baltatzi M, et al. Impaired fasting glucose in hypertensive patients: prevalence and cross-sectional analysis of associations with cardiovascular disease. Diabetes Technol Ther. 2013;15(6):475-480. doi:10.1089/dia.2012.0336

13. Zhao R, Duan X, Wu Y, Zhang Q, Chen Y. Association of exposure to Chinese famine in early life with the incidence of hypertension in adulthood: A 22-year cohort study. Nutr Metab Cardiovasc Dis. 2019;29(11):1237-1244. doi:10.1016/j.numecd.2019.07.008

14. James PA, Oparil S, Carter BL, et al. 2014 evidence-based guideline for the management of high blood pressure in adults: report from the panel members appointed to the Eighth Joint National Committee (JNC 8). JAMA. 2014;311(5):507-520. doi:10.1001/ jama.2013.284427

15. Association AD Classification and Diagnosis of Diabetes: standards of Medical Care in Diabetes-2018. Diabetes Care. 2018;41(Suppl 1): S13-S27. doi:10.2337/dc18-S002

16. Xu RB, Kong X, Xu BP, et al. Longitudinal association between fasting blood glucose concentrations and first stroke in hypertensive adults in China: effect of folic acid intervention. Am J Clin Nutr. 2017;105(3):564-570. doi:10.3945/ajcn.116.145656

17. Jin C, Li G, Rexrode KM, et al. Prospective study of fasting blood glucose and intracerebral hemorrhagic risk. Stroke. 2018;49(1):2733. doi:10.1161/STROKEAHA.117.019189

18. Doi Y, Ninomiya T, Hata J, et al. Impact of glucose tolerance status on development of ischemic stroke and coronary heart disease in a general Japanese population: the Hisayama study. Stroke. 2010;41 (2):203-209. doi:10.1161/STROKEAHA.109.564708

19. Sarwar N, Gao P, Seshasai SR, et al. Diabetes mellitus, fasting blood glucose concentration, and risk of vascular disease: a collaborative meta-analysis of 102 prospective studies. Lancet. 2010;375 (9733):2215-2222. doi:10.1016/S0140-6736(10)60484-9

20. Ohkubo T, Asayama K, Kikuya M, et al. Prediction of ischaemic and haemorrhagic stroke by self-measured blood pressure at home: the Ohasama study. Blood Press Monit. 2004;9(6):315-320. doi:10.1097/ 00126097-200412000-00009

21. Lee JS, Chang PY, Zhang Y, et al. Triglyceride and HDL-C Dyslipidemia and Risks of Coronary Heart Disease and Ischemic Stroke by Glycemic Dysregulation Status: the Strong Heart Study. Diabetes Care. 2017;40(4):529-537. doi:10.2337/dc16-1958

22. Mitchell AB, Cole JW, McArdle PF, et al. Obesity increases risk of ischemic stroke in young adults. Stroke. 2015;46(6):1690-1692. doi:10.1161/STROKEAHA.115.008940

23. Turner GM, Calvert M, Feltham MG, et al. Under-prescribing of prevention drugs and primary prevention of stroke and transient ischaemic attack in UK general practice: a retrospective analysis. PLoS Med. 2016;13(11):e1002169. doi:10.1371/journal.pmed.1002169

24. Meschia JF, Bushnell C, Boden-Albala B, et al. Guidelines for the primary prevention of stroke: a statement for healthcare professionals from the American Heart Association/American Stroke Association. Stroke. 2014;45(12):3754-3832. doi:10.1161/STR.0000000000000046

25. Katsanos AH, Filippatou A, Manios E, et al. Blood pressure reduction and secondary stroke prevention: a systematic review and metaregression analysis of randomized clinical trials. Hypertension. 2017;69(1):171-179. doi:10.1161/HYPERTENSIONAHA.116.08485

26. Zhong P, Wu D, Ye X, et al. Secondary prevention of major cerebrovascular events with seven different statins: a multi-treatment meta-analysis. Drug Des Devel Ther. 2017;11:2517-2526. doi:10.2147/DDDT.S135785 
27. Hankey GJ. Stroke. Lancet. 2017;389(10069):641-654. doi:10.1016/ S0140-6736(16)30962-X
28. Steiger N, Cifu AS. Primary Prevention of Stroke. JAMA. 2016;316 (6):658-659. doi:10.1001/jama.2016.5529

\section{Publish your work in this journal}

Risk Management and Healthcare Policy is an international, peerreviewed, open access journal focusing on all aspects of public health, policy, and preventative measures to promote good health and improve morbidity and mortality in the population. The journal welcomes submitted papers covering original research, basic science, clinical \& epidemiological studies, reviews and evaluations, guidelines, expert opinion and commentary, case reports and extended reports. The manuscript management system is completely online and includes a very quick and fair peer-review system, which is all easy to use. Visit http://www.dovepress.com/testimonials.php to read real quotes from published authors. 